\title{
The Impact of Digital Books on Reading in Arabic Orthography
}

\author{
Salim Abu-Rabia1, Madonna Hanna² \\ ${ }^{1}$ Faculty of Education, University of Haifa, Haifa, Israel \\ ${ }^{2}$ Ministry of Education, Haifa, Israel \\ Email: salimar@edu.haifa.ac.il
}

How to cite this paper: Abu-Rabia, S., \& Hanna, M. (2022). The Impact of Digital Books on Reading in Arabic Orthography. Creative Education, 13, 296-319. https://doi.org/10.4236/ce.2022.131018

Received: December 15, 2021

Accepted: January 25, 2022

Published: January 28, 2022

Copyright $\odot 2022$ by author(s) and Scientific Research Publishing Inc. This work is licensed under the Creative Commons Attribution International License (CC BY 4.0).

http://creativecommons.org/licenses/by/4.0/

\begin{abstract}
Background: This study examined the effectiveness of digital books in improving reading and reading comprehension among seventh-grade Arab students who have been defined as having difficulty reading. Method: This study sampled 120 students. Sixty students studied Arabic using a digital book, and sixty students at another school studied the same material in a printed version. The students are Arabic-speakers and are considered poor readers. The study population were located at the beginning of the school year based on the results of the AMIT assessment (a tool for mapping students' ability in reading comprehension) in order to test the effectiveness of digital books on strengthening reading skills and comprehension. This study examined students in Arabic. The students were administered a test of reading and reading comprehension using digital texts. Results: The study indicated that using digital books did indeed improve reading comprehension skills in Arabic (in all dimensions of understanding) among Arab students struggling to read. On the other hand, the use of the digital books did not seem to affect reading accuracy skills among these students. Conclusions: Learning Arabic via digital books can improve poor Arabic readers in Arabic.
\end{abstract}

\section{Keywords}

Digital Books, Diglossia, Arabic Orthography, Reading Comprehension, Reading Fluency, Reading Accuracy, Computerized Learning, E-Learning, AMIT Assessment, Digital Literacy, Digital Reading

\section{Introduction}

This study will examine the effectiveness of digital books in improving reading and comprehension among seventh grade Arab students who struggle with reading and reading comprehension. 
Now, at the beginning of the 21st century, we are in the midst of a digital revolution, whose roots deepened during the last third of the 20th century. Its influence is evident in all areas of our lives. It impacts human behavior, lifestyle, and the ways in which people receive information. Given the rapid and ongoing development of digital technologies, students today must use a growing range of cognitive skills to perform tasks and solve problems in a digital environment. In the literature, these skills are called "digital literacy".

The Israeli educational system is eager to embrace and implement technological developments in education because the new learning technologies greatly expand the potential for learning and possible learning styles, in both individual and collaborative learning. In recent years, schools in Israel have begun to emphasize the use of digital books as part of their educational programs in order to develop and strengthen a gamut of literacy skills and strategies for meaningful learning.

Since the 2015-2016 school year, Israeli schools have been incorporating digital books as an integral part of the school curriculum. Digital books are used as tools to promote meaningful learning and more effective learning processes. Eshet (2012) found that the use of digital books promotes various types of literacy required to process multichannel information, such as innovation and creativity, critical thinking and problem solving, and collaboration. Online and computerized learning environments make it possible to achieve the desired educational and academic goals. They also have the potential to effect substantial change in the teaching and learning processes in schools. In addition, integrating digital books into the curriculum facilitates the creation of a learning environment that will help students successfully acquire various learning skills (Eshet, 2012).

Today, there is an accelerated trend of converting learning materials from traditional textbooks, to an active and dynamic teaching-learning environment, in which teaching materials are made accessible as digital learning units for the benefit of both teacher and student. Hence the importance of this study, which aims to examine whether the use of digital books helps improve reading and reading comprehension among students struggling with the Arabic language.

\section{Literature Review}

\section{Reading acquisition in Arabic}

Reading acquisition is a very challenging process for young learners, because the process requires the development of both psycho-linguistic and cognitive abilities (Taha, 2013). In every language, the acquisition of reading skills requires an understanding that the writing system, which is constructed of written units, represents spoken units. However, it is also important to learn the way in which these written units represent the phonological units (Bar-On, 2005). Reading and pronunciation processes in Arabic are influenced by its linguistic and or- 
thographic uniqueness (Taha, 2013). Reading is a complex process that includes phonological, orthographic, and syntactic development, and working memory skills (Abu-Rabia \& Abu-Rahmoun, 2012). Since the spoken Arabic language is significantly different and distinct from the written one, this affects the phonological representations among speakers of Arabic. Indeed, some attribute the delay in the development of phonological awareness among Arab children, to the gap between the oral and written languages (Taha, 2013).

A study conducted by Abu-Rabia \& Siegel (2003) found that there is a definite link between the acquisition of reading skills and oral words by Arab students who studied in three languages (Arabic, Hebrew and English), and syntactic awareness skills in the three languages. Syntactic awareness is the ability to understand the basic grammatical structure of the language. Moreover, the study found that learning three languages is not detrimental to the students' ability to acquire reading skills. In fact, it seems that learning three languages can benefit students in this regard.

All cognitive models of reading, without exception, include the phonological, orthographic and semantic representations of words, in addition to the mapping system and the interactions that occur among these words (Cremer \& Schoonen, 2012; Duff, 2015; Hohenstein, 2013; Isakson \& Spyridakis, 2003; Milin et al., 2017; Perfetti \& Stafura, 2014). The dual route approach deals with the effects of reciprocity and interactivity among various indices that are the foundation of reading, such as the effect of semantic knowledge on orthography and vice versa. In computer models based on the dual route approach, activating semantic knowledge is not necessary or, alternatively, it is necessary for the purpose of identifying words spoken out loud (Courteau et al., 2013; Duff, 2015; Cremer \& Schoonen, 2012; Hohenstein, 2013). On the other hand, according to the triangular demonstration model, it seems that semantic knowledge affects learning and the processing of the mapping that occurs between the written and spoken forms of words. To be more specific, semantic knowledge predicts the various reading processes (Courteau et al., 2013; Duff, 2015; Cremer \& Schoonen, 2012; Milin, Divjak, \& Baayen, 2017). However, the various experimental studies have almost neglected the fundamental nature of the various semantic representations. Moreover, they have neglected the way in which these representations affect the reading of words and reading development in general. Language development studies provide us with extremely important key insights to understand the processes of transition from reading done out loud (with effort) and proficient, quiet reading (Cremer, 2013; Cremer \& Schoonen, 2012; Duff, 2015; Isakson \& Spyridakis, 2003; Hohenstein, 2013).

\section{Reading Comprehension}

The development of reading comprehension skills is the primary and ultimate goal of all reading acquisition processes. Not surprisingly a great many researchers of various languages have engaged the topic of reading comprehension (Curinga, 2014a; Curinga, 2014b; Deacon, Kieffer, \& Laroche, 2014; Kirby et al., 2012). One of the most popular and common theories for understanding the 
process of reading comprehension is the Simple View of Reading (SVR) Model. This model defines reading comprehension as a result of coding and listening comprehension. The model explains $70 \%-83 \%$ of the variance in reading comprehension in English, in which the contribution of encoding and reading comprehension varies as a function of the readers' level. The degree of orthographic transparency and a number of other characteristics of languages, affect reading comprehension in these languages. The conventional scholarly explanation for this is that reading acquisition in an opaque language (also known as a deep language) is far more challenging and difficult than reading acquisition in languages with a transparent orthography. This is because the ambiguity surrounding the grapho-phonemic connections in languages with opaque and non-transparent orthography renders the task of encoding much slower, and therefore their contribution to reading comprehension is much slower (Asadi et al., 2016).

Reading comprehension is an interactive and evolutionary process. It deals simultaneously with construction and extraction of the implications arising from the text (Asadi et al., 2016; Curinga, 2014a; Curinga, 2014b; Kirby et al., 2012). Therefore, there are at least two major ways by which we can assume that morphological awareness can influence the process of reading comprehension (Deacon, Kieffer, \& Laroche, 2014; Kieffer \& Lesaux, 2008; Lam, 2009). First, the students' knowledge of the words can significantly facilitate their understanding of texts that include morphologically complex words. In this context, morphological awareness is one aspect of what is called the "depth" of lexical knowledge, or wealth of knowledge about individual words (Asadi et al., 2016; Curinga, 2014a; Curinga, 2014b; Kieffer \& Lesaux, 2008). In this case, understanding the morphological connectivity can affect reading comprehension independently, i.e. without any connection to the vocabulary breadth that the learners possess $(\mathrm{Cu}$ ringa, 2014b; Deacon, Kieffer, \& Laroche, 2014; Kieffer \& Lesaux, 2008; Kirby et al., 2012). Second, the learners' ability to dissect complete words on the morphological level can result in an optimal and desirable situation in which they successfully learn new words. This process is the foundation for the students' ability to understand texts (Kieffer \& Lesaux, 2008).

\section{Key Factors in Reading Acquisition in Arabic}

\section{Diglossia}

"Diglossia" is defined as a linguistic state in which two forms of the same language are used in a particular society, side by side. There is a clear distinction between the language and its speakers, the separation of the social roles that each of the languages forms serve, and linguistic proximity between the two codes competing over the same language (Ferguson, 1959). Diglossia does not mean bilingualism, and there is a significant difference between these terms. Bilingualism describes a linguistic situation in which two languages are used at the same time (Almosa, 2003). As stated, the Arabic language has two forms: a spoken 
form (Alamia), and a written form (Alfosha) (Ferguson, 1959), which is bound to a broad scale system of very conservative and rigid rules. This is because it is the language of Muslims' holy book, the Koran (Almosa, 2003). The written Arabic language is the standard form, while the dynamism that characterizes spoken Arabic creates a constantly growing gap between the two forms of Arabic (Maamouri, 1998). Hodges and Harris (Harris \& Hodges, 1981) refer to the written language as "high", and to the spoken language as "low". Beyond the aspect of prestige, the differences between the two forms of the language involve the aspect of acquisition. While the spoken language is acquired in a natural way, since it is a native language, the standard language is taught as part of the school curriculum in the formal educational system. The individual learns the grammar of the spoken language without receiving explicit instruction. By contrast, the student studies the grammar of the written language intensively. There is also a functional difference between the two forms of the language (Ferguson, 1959). The spoken language is used in everyday routine discourse. The written form of the language is used for formal communication, such as correspondence with official institutions, the press, literature, and textbooks (Almosa, 2003).

Given the diglossia that is very typical to the Arabic language, there seems to be a concrete for familiarization with the domain of phonological awareness while focusing on the differences between the language's spoken and written forms (Saiegh-Haddad, 2003, 2004). The standard Arabic language has 28 consonants and 6 vowels, 3 long and 3 short. Additionally, the standard language has four phonemes that do not appear in the dialect, and which children do not know before acquiring reading skills: The voiced inter-dental fricative (ذ); the voiceless inter-dental fricative (ث); the emphatic voiced inter-dental fricative voice (b); and the sound (ق). Diglossia in Arabic creates the phenomenon of "lexical word pairs" in which there are two words, one in the spoken language and one in the standard language, that have the same meaning (Ferguson, 1959).

Ibrahim (2010) wondered whether the native Arabic speaker processes the literary language as a second language, or whether he extends the lexicon of the language spoken used in everyday life to include also the words and linguistic rules that are at the base of classical Arabic. In other words, is the structural gap between the literary language and the spoken language a case of diglossia, or are we dealing with a phenomenon that extends into a state of bilingualism? To address this question, He examined the psychological reality of the two phenomena by checking the potential effects of the lexical organization in the cognitive system of high school students fluent in the literary language. The study's main finding indicates that the semantic change between words in literary Arabic and in spoken Arabic was similar to those obtained under a condition of semantic change between words in Hebrew and words in spoken Arabic, more than in the semantic change pattern between words in spoken and target words in the same language. 


\section{The uniqueness of Arabic orthography}

Arabic script consists of 28 letters, all but three of which are consonants (Abu-Rabia, 2007). The Arabic language consists of 29 consonants and 8 vowels (Mohamed, Elbert, \& Landerl, 2011). Most Arabic letters have various forms in which they can be written, depending on the letters' location in the word: beginning, middle, or end. However, the basic and fundamental form of the letter is always maintained. Moreover, the letters are divided into categories according to their basic form. The difference between them is reflected in the number of dots above, below or within the letter. It is worth noting that 15 out of the 28 letters in the Arabic language have dots. Ten of the letters contain just one dot, three letters have two dots, and two letters have three dots, which are part of the consonant letters. In addition to dots, there are diacritical accent marks that contribute to the phonological Arabic alphabet. Words in Arabic are a combination of vowels and consonants. To enable the appropriate level of accuracy in reading Arabic, it is necessary to vocalize the words according to their grammatical roles in the sentence (Abu-Rabia, 2007).

Arabic belongs to the cluster of languages known as "Semitic languages". Unlike other Semitic languages, spoken Arabic differs from one geographic location to another. This difference is expressed and reflected in practically all of the linguistic fields: phonological, morphological, syntactic and semantic. Thus, for example, in some geographic areas, it is possible to identify the existence of certain phonemes which are totally absent in other geographical areas. In addition, the meaning of certain words varies from one place to another (Taha, 2013).

Vowelized Arabic orthography is defined as transparent, while the non-vowelized orthography is considered deep (Abu-Rabia, 1999; Taha, 2013; Abu-Rabia \& Siegel, 2003). Like in Arabic, Hebrew language learners also learn to read texts with vowelization at the end of third grade. However, reading without vowelization presents the reader with two significant challenges: 1) completion of phonological information missing from the non-vocalized words in the text; 2) deciphering correctly all of the homographic words in the text (Bar-On, 2005).

Arabic is different from English in a number of ways: the form of the letters, the orthographic depth, the reading direction, homophonicity and homographicity, morphology, vowels and diglossia that constitutes one of the most important foundations. In morphological terms, the Arabic language is defined as "consonantal" rather than as "alphabetical", is considered to be more complicated than English, which relies on an array of both free and bound phonemes. Moreover, unlike in English, the Arabic writing system does not display the short vowels (Stein, 2010). Orthography in English is not regular (as it is in Arabic), so that each set of letters combined in one form or another, behaves differently (Abu-Rabia, 1999).

The Arabic orthographic system is considered one of the most complex among all languages, since the conceptual separation of the letters can affect li- 
teracy acquisition process, speed in the identification of words and, consequently, also the reading comprehension. Moreover, Arabic is characterized by the similarity among its 29 letters. The Arabic morphological system is considered rich and thick. Some researchers have stressed that the morphological units in Arabic are an integral part of orthographic knowledge. In addition, there is empirical evidence to suggest that Arabic morphology is one of the organizational principles of the mental lexicon, so that it contributes significantly to the process of visual identification of words (Asadi et al., 2016).

\section{A learning environment saturated with technology}

Recent years have seen a growing trend in the development and implementation of ICT technology-intensive environments, by educators who are working hard on developing and implementing these technologies. The effectiveness of the computerized learning environment was assessed based on uniform criteria of pedagogical efficiency that compare between the computerized learning environment and the traditional environment. Yet such a comparison does not accentuate, reliably, the real capabilities of the computerized learning environment (Huda, Haron, Ripin, Hehsan, \& Yaacob, 2017). It is possible to implement and instill the computerized learning environment in schools quickly and very efficiently. Nevertheless, despite the fact that schools around Israel have been equipped with a variety of cutting edge technology, and high-speed Internet access, in addition to special training that teachers undergo to learn how to use the new teaching tools-teachers rarely use ICT in the classroom (Hanafi, Said, Wahab, \& Samsuddin, 2017). The Israeli education system has started to adapt, by means of a gradual process in which the Ministry of Education is turning regular classrooms into "smart classrooms." A "smart classroom" is one that includes a computer connected to the internet and to a projector, a smart board, and a computer for each child or group of children. The problem is not the interactive board in the classroom is not used-but rather, how it is used. Often, it is used exactly in the same way as a regular blackboard (Tondeur, Aesaert, Pynoo, van Braak, Fraeyman, \& Erstad, 2017). The application of innovative technologies in schools is a complicated process that requires fundamental, substantial and profound cultural change at the systemic, managerial, technological and pedagogical levels at the school (Huda et al., 2017). And it takes time.

\section{The Definition of "Digital Textbook"}

The digital textbook is a technological-pedagogical application that has the potential to expand the teacher and student's autonomy in the management of the learning-teaching process and to implement a new balance of power relations in the classroom (Cooke, Philpott, Evans, \& Spruce, 2016). According to the definition on the Ministry of Education's ICT Program website: “A digital book is a digital object that contains content that combines the features of the traditional book with features of the electronic environment" (Kucirkova, Littleton, \& Cre- 
min, 2017). Digital textbooks were developed specifically for the Web environment, and they are characterized by visual richness and interactivity. According to researchers' assessments, digital textbooks provide an innovative learning tool that allows teachers to teach in a way that was previously impossible, while addressing the needs of students in the era of the "knowledge society".

In September 2011, the Israeli education ministry's director general issued a circular entitled "Digital Textbooks". The document details the steps for implementing the decision to support the development and publishing digital textbooks used in schools in Israel.

\section{Digital Books and Improvement of Reading and Reading Comprehension Skills}

One of the salient features of reading from a digital book is reading in non-linear environments. This feature bears the potential to promote creative and meaningful learning, so that students have an active role in the instruction process. A digital book is a popular way of making verbal texts accessible to the reader. The use of digital books has increased in recent years because it is easier to transfer and receive information to and from them, and they can serve a wide range of learning objectives (Kucirkova et al., 2017).

Studies (Cooke et al., 2016) suggest that activity done with a digital book improves students' phonological awareness, detection capability and their ability to read written words. In addition, learning through a digital book helps learners achieve improved reading accuracy, reading fluency, improves their expressive capabilities, and their ability to retell the story that was presented to them in this medium.

Reading from a computer screen has been found to be less controlled than reading from a printed book. On the one hand, there are those who believe that in transitioning to the use of digital books in schools there lies a tremendous potential to improve learning and achievement. On the other hand, some studies have shown repeatedly that in order to learn thoroughly, people prefer to learn from a printed book rather than from a digital display. They attribute the reluctance to learn from electronic displays because to the lack of comfort associated with reading from an electronic display (Huang \& Liang, 2015).

In contrast to traditional books, reading text on a digital book allows the reader to work with hypertext links (which allows the reader to move from one page to another). The hypertext enables a deeper understanding of complex tasks. In transitions between two pages, the reader develops his creative thinking ability by means of various associations that he constructs for himself (Ang, Orozco, Gijbels, \& Van den Bossche, 2018). Reading with hypertexts requires cognitive flexibility, something that makes learning fun on the one hand, and on the other hand the reader is able to improve various comprehension skills and improve the various dimensions of achievement and reading comprehension (Huang \& Liang, 2015). 
There is a positive correlation between phonological awareness and success in reading acquisition. However direct intervention is needed to aid in the development of phonological awareness. Applications and the use of digital books have been found to be effective ways to train phonological awareness. They also enable the reader to maintain skills were acquired over time, even after the intervention.

A study (Jones, Chik, \& Hafner, 2015) that examined the impact of learning by means of digital book on fluency and accuracy in reading, indicated that innovative reading technologies based on digital books promote reading fluency. The study examined reading fluency among high school students who studied with digital books, and compared them to students who studied using regular books. The study showed that the use of the computer and digital texts has positive effects in promoting reading fluency. Moreover, learning in a digital environment increased the motivation to read.

Given the literature review presented above, the following research question arises: Does the use of digital books help improve reading, fluency and reading comprehension skills among typical seventh-grade Arab students (at a state-funded junior high school) who have difficulty reading?

\section{Hypotheses}

- Using digital books will improve the reading accuracy and fluency in Arabic among typical seventh-grade Arab students (at a state-funded junior high school) who have difficulty reading.

- Using digital books will improve comprehension skills (in all dimensions of understanding) in Arabic among typical seventh-grade Arab students (at a state-funded junior high school) who have difficulty reading.

\section{Method}

\section{Participants}

The study was conducted at a comprehensive middle school in the Arab Sector in Northern Israel. The school has six grades (from seventh grade to eleventh grade). Each grade has six heterogeneous classes, with about 30 students in each class (boys and girls study together). Most of the students are from the village in which the school is located, but there are also some students who come from nearby villages. The main teaching method at the school is digital, so the school's vision supports a digital learning environment that advances meaningful learning and the development of 21 st century skills. Students at this school come to classes with laptop computers and study most of the material (except mathematics) through digital books in online, computerized environments.

The study sampled 60 students. Thirty of them studied Arabic (reading comprehension) using digital books, and 30 students studied the printed version of the same book at another school. The students speak Arabic as their mother 
tongue, and they are at the weak-intermediate level of learning.

The study's population was located at the beginning of the school year based on the "AMIT" assessment results. The AMIT Assessment is a tool used to map language skills of all students at the beginning of seventh grade, and it is a tool to identify students struggling with basic reading comprehension skills in Arabic. The test was designed by RAMA (the National Authority for Measurement and Evaluation in 2008). The test defined levels of performance in reading comprehension at three performance levels: "basic", "low", "very low". A score range was defined for each level. Below are details of the range of scores:

- Basic level (B)-Score range (196 - 204): Students fluent in all comprehension skills.

- Low level (L)-Score range (181 - 195): Struggling students. Partially mastered reading comprehension skills. This is a group found to have a learning gap in Arabic language skills.

- Very low level (L-)-Score range (154 - 180): These are general students who have been diagnosed with a learning disability and participate in integration lessons.

The study group included 60 students at the low level (L) and very low level (L-). Parallel to this, based on the results of the mapping carried out at another school, there was a control group of 60 students who have been identified as struggling and who are at the same levels-low (L) and very low level (L-).

\section{Research tools and learning method}

In order to test the effectiveness of the digital book on reading and reading comprehension skills, this study assessed the students in the discipline of Arabic (as a native language)-reading comprehension, using texts from the digital book “العربية لغنتا" (Arabic, Our Language). Each student sat in front of a personal computer and browsed the electronic book, and the teacher taught and presented the text using the projector. Students read the digital text and answered questions about it on the computer (according to the teacher's instructions). Additional information and highlights for each of the learning units in the book is provided via a hyperlink. In contrast, the control group studied the same reading comprehension texts in a printed version of the same book, and answered the questions in a notebook.

\section{The research process and the research network}

The research was conducted using an experimental study and took place in two Arab schools in the north of Israel: a school that teaches using a digital book and another school that teaches the same book in the printed version. The study involved 120 seventh grade students. Sixty of them used a digital book and sixty used an ordinary book.

The two groups (test and control) received the tests in the same manner. The steps of the study are as follows:

1) At the beginning of the year:

- Students were given an assessment (the AMIT test)—using the text " هل تنتحر 
الحيثان حقا??" (Do Whales Really Commit Suicide?)—in order to test their reading comprehension skills.

- Students were given a reading comprehension text, "الجدة واحفادها" (Grandmother and Her Grandchildren) to test reading accuracy and fluency.

\section{Accuracy}

The formula for finding percentages of errors:

$100 \times$ number of errors

Number of words in the text

Up to $7 \%$ errors-in the normal range,

$8 \%-10 \%$ errors-reading skills are lower than normal,

Over $10 \%$ errors-the child has difficulty reading.

Evaluation of fluency:

The formula for determining the reading rate/fluency:

$60 \times$ number of words in the text

Amount of time spent reading, in seconds

(Normative indicators-120 Words per minute for seventh grade students).

2) During the experiment: the experimental group studied the digital book “" (Arabic, Our Language) for three months, while the control group at the same school studied the same material in the printed version. Arabic our language

3) After the experiment period (three months): Students were administered a new AMIT assessment, using the text "لغوص" (Diving) to test reading comprehension skills, in order to track students' progress. The students were also given a reading test-using the text " لجدة واحفادها" (Grandmother and Her Grandchildren) in order to track progress in their reading fluency and accuracy.

\section{Statistical Analysis}

Descriptive statistics were conducted in order to report on the means and data dispersion. Inferential statistics aimed at examining the research hypotheses using chi-square tests for independent and dependent samples.

\section{Results}

\section{Descriptive statistics}

In the findings section, the data will be presented descriptively and statistical tests will be performed to examine the research hypotheses.

The relationship between the school and student level was checked using the chi square to test the independence between the variables.

Since the variables in the AMIT score (reflecting reading fluency and accuracy), do not have a normal distribution, the Kolmogorov-Smirnov test was used.

Examination of the differences between the values of the variables at the beginning of the year and after three months will be reviewed by a nonparametric test, the Mann-Whitney test. 
In addition, the differences in scores between the two types of schools will be checked using the Wilcoxon signed-ranks test.

Explanation of the three levels:

Basic level (B)-score range (196 - 204): Students with mastery of all comprehension skills.

Low level (L) - score range (181 - 195): Struggling students, who have partially mastered reading comprehension skills. This is a group with a learning gap in Arabic language skills.

Very low level (L-)-score range (154 - 180): Generally these are students who have been diagnosed with and suffer from a learning disability and receive integration lessons.

Table 1 shows the data at the two schools at the beginning of the school year and after the experiment period (three months later). At the beginning of the educational year, 120 seventh grade students were sampled: 60 students who attend a regular school and 60 students who attend a school that uses computer technology. 31 of the students were rated level (L), and 89 were rated level (L).

After three months, 26 of the students were rated level (B), 22 students were rated level (L), and 72 students were rated level (L).

Table 2 shows the scores and standard deviations (SD) for the following variables: AMIT assessment score, reading fluency and reading accuracy at the two schools at the beginning of the year and after three months.

Table 1. School frequency data.

\begin{tabular}{ccccc}
\hline School data & & $\%$ & N & Total \\
\hline School & Regular & 50 & 60 & 120 \\
& E-Learning & 60 & 60 & \\
\hline Student level start of year, & $(\mathrm{L}-)$ & 25 & 31 & 120 \\
AMIT assessment & $(\mathrm{L})$ & 74.4 & 89 & \\
\hline $\begin{array}{c}\text { Student level after 3 months, } \\
\text { AMIT assessment }\end{array}$ & $(\mathrm{L})$ & 60 & 72 & \\
& $(\mathrm{~L}-)$ & 18.3 & 22 & 120 \\
\hline
\end{tabular}

Table 2. Display of scores and standard deviations for AMIT, fluency and accuracy of reading scores for the two schools together.

\begin{tabular}{ccccc}
\hline $\begin{array}{c}\text { Variable/time } \\
\text { (start of year and } \\
\text { after 3 months) }\end{array}$ & \multicolumn{2}{c}{ Beginning of the school year } & \multicolumn{2}{c}{ After three months } \\
\cline { 2 - 5 } & Score & SD & Score & SD \\
\hline AMIT test score & 184.22 & 9.98 & 188.38 & 10.04 \\
Reading fluency & 93.52 & 17.67 & 100.69 & 14.21 \\
Reading accuracy & 0.0697 & 0.0296 & 0.0647 & 0.0608 \\
\hline
\end{tabular}

Total number of students examined at the two schools: 120 . 
The averages of the three variables (AMIT score, fluency and reading accuracy), showed that the average AMIT test score at the beginning of the school year in both schools was 184.22 (9.89), and after three months, the average was 188.38 (10.04). The average reading fluency score in both schools at the beginning of the year was 93.52 (17.67) and after three months it was 100.69 (14.21). The average reading accuracy score at both schools at the beginning of the year was 0.0697 (0.0296) and after three months, the average was 0.0647 (0.0608).

Table 3 shows the pupils' levels at both schools, before and after three months. According to a chi-squared test, significant differences were found in the students' levels between the students at one school versus the school after three months $\left(\chi^{2}=24.794, p<0.001\right)$.

There was a change in the students' levels from the beginning of the year compared to after three months, and especially in the progress to level (B). After three months, 38.3\% (23 students) of the students at the school that uses computerized learning were rated (B), while at the regular school only $5 \%$ (5 students) were rated (B). Moreover, after three months, $6.7 \%$ of students (4 students) at the school that uses online learning were rated (L-), compared to $30 \%$ of students (18 students) at the regular school who ranked (L-) (Table 4).

Table 3. Examination of differences between the student level and school type.

\begin{tabular}{|c|c|c|c|c|}
\hline \multirow{2}{*}{ Student level/School } & \multicolumn{2}{|c|}{ Computerized school } & \multicolumn{2}{|c|}{ Regular schoo } \\
\hline & $\mathbf{N}$ & $\%$ & $\mathbf{N}$ & $\%$ \\
\hline Students at (L) level, start of year & 47 & 78.3 & 42 & 70 \\
\hline Students at (L-) level, start of year & 13 & 27.7 & 18 & 30 \\
\hline Students at (B) level, start of year & 0 & 0 & 0 & 0 \\
\hline Total number of students & \multicolumn{2}{|c|}{60} & \multicolumn{2}{|c|}{60} \\
\hline Students at (L) after 3 months & 33 & 55 & 39 & 65 \\
\hline Students at (L-) after 3 months & 4 & 6.7 & 18 & 30 \\
\hline Students at (B) after 3 months & 23 & 38.3 & 3 & 5 \\
\hline Total number of students & \multicolumn{2}{|c|}{60} & \multicolumn{2}{|c|}{60} \\
\hline
\end{tabular}

Table 4. Examination of the relationship between AMIT, reading fluency and reading accuracy, and the kind of school/in every school.

\begin{tabular}{ccccc}
\hline \multirow{2}{*}{ Variable/Type of School } & \multicolumn{2}{c}{ Regular school } & \multicolumn{2}{c}{ Computerized school } \\
\cline { 2 - 5 } & $\mathrm{N}$ & $\%$ & $\mathrm{~N}$ & $\%$ \\
\hline AMIT score, start of year & 182.78 & 10.95 & 185.65 & 8.56 \\
Reading fluency, start of year & 92.58 & 18.81 & 94.45 & 16.55 \\
Reading accuracy, start of year & 0.078 & 0.0349 & 0.0617 & 2.01 \\
AMIT score after 3 months & 183.47 & 10.83 & 193.28 & 6.8 \\
Reading fluency after 3 months & 100.17 & 10.26 & 101.22 & 13.2 \\
Reading accuracy after 3 months & 0.0727 & 8.43 & 0.567 & 1.49 \\
\hline
\end{tabular}




\section{- The relationship between scores and the type of school:}

According to the Mann-Whitney test, statistically significant differences in reading accuracy between the two schools were found at the beginning of the year $(U=1279, p=0.006)$. The average reading accuracy percentage at the school at the beginning of the year was $7.78 \%$ (SD = 3.49\%), while at the computerized learning school it was $6.17 \%(2.01)$.

In addition, after three months, there are statistically significant differences between the schools on the AMIT test $(\mathrm{U}=747, p<0.001)$, and in reading accuracy $(\mathrm{U}=1399, p=0.031)$. The average AMIT score at the regular school was 183.47 (standard deviation $=10.83$ ), while at the school that uses computerized learning, the average is 193.28 (6.8).

At the beginning of the year, the AMIT score was slightly lower at the regular school than at the computerized learning school, but these differences are not statistically significant (182.78 vs. 185.65).

The average reading accuracy percentage at the regular school was $7.27 \%$ (8.436\%), and at the computerized learning school it was 5.67\% (1.497\%).

\section{- The relationship between the scores within the school}

According to the Wilcoxon signed-ranks test, at the school with computerized learning, there were significant differences in accuracy and reading fluency between the beginning of the year and after three months. At the beginning of the year, the average reading accuracy was $6.17 \%(2.015 \%)$, while after three months the students' average score was $5.67 \%(1.497 \%)$. The average reading fluency at the beginning of the year was 94.45 (16.549), and after three months the average reading fluency was 101.22 (13.186).

There is also a significant difference in the AMIT score at the beginning of the year and after three months (the average score rose). At the beginning of the year, the average score was on the AMIT test was 185.65 (8.56) and after the experiment period it rose to 193.28 (6.8).

At the regular school, there were also significant differences between reading accuracy and reading fluency early in the year and after three months. At the beginning of the year, the average reading accuracy average was $7.78 \%$ (3.497\%), while after three-months, students' average score is $7.27 \%$ (8.436\%). The average reading fluency at the beginning of the year was 92.58 (18.812), and after three months, the average reading fluency was 100.17 (15.258).

There is no significant difference at the regular school on the AMIT assessment score. The average score at the beginning of the year was 182.78 (10.95), and after three months, the average score was 183.47 (10.83).

\section{Discussion}

This study's purpose is to examine whether the use of digital books helps improve reading and reading comprehension among typical Arab students who experience difficulty reading, in a seventh grade state junior high school. The findings indicate that: 
1) The first hypothesis, that proposes that using digital book will improve the reading accuracy and fluency in Arabic among typical Arab students who have difficulty reading, in seventh grade, in a state junior high school state, has been refuted.

2) The second hypothesis that proposes that the use of digital books will improve comprehension skills (in all dimensions of understanding) in Arabic among typical Arab students who struggle, in seventh grade, junior high school state, has been corroborated.

Discussion of each of this study's two hypotheses:

\section{The first hypothesis}

The first hypothesis, which holds that using digital books will improve the reading accuracy and fluency in Arabic among Arab students in the seventh grade, junior high school state, has been refuted.

The main factor underlying the refutation of the first hypothesis is that among students who have difficulty reading, there are significant factors other than the type of book (a regular book versus a digital book), that underlie their ability to read fluently and accurately. In terms of fluency and accuracy of reading amidst struggling Arab students in the seventh grade, no significant differences were found between the scores of students in the regular school versus in the school using digital learning. These findings are not consistent with the findings of international studies, including e-Pirls (RAMA, 2017) and Pisa (2018) that indicated that student achievement in reading scientific texts in a computerized environment are higher than their achievements when reading printed scientific texts.

One of the main reasons for the refutation of the first hypothesis is that the absence of prior knowledge in the field with which the text deals could hurt the reading pace. Lack of knowledge may overload the working memory. When the reader has prior knowledge of the subject text, the load decreases and he can read more easily. For example, a child reading about a unique natural phenomenon like a "Tsunami" may use his knowledge about the phenomenon to accelerate his reading pace. The teacher can help in two ways: by increasing the reader's prior knowledge and by raising the student's awareness to the need to link new information to prior knowledge, and by developing strategies that will help the learner to identify his prior knowledge, that is relevant to the text and determine whether it is enough to read (Share, 2008).

In addition to all of the above, we can interpret the refutation of the first hypothesis by the clear and significant impact of orthography on reading fluency. In this context, Hudson and others (Hudson et al., 2008) examined orthographic awareness as a factor affecting reading fluency, and also examined the relationship between sensitivity to the composition of letters and reading fluency. There is much scientific evidence that shows that low phonological awareness damages orthographic awareness. Intervention studies have shown that training phonological awareness significantly improves orthographic awareness, but does not 
improve reading fluency. Additional studies that examine the relationship between language components and difficulties in reading fluency, deal with dyslexic adults who received remedial education for many years and learned to compensate and to circumvent the difficulties. The studies found that this reading group reads accurately, but very slowly, a matter which is counterproductive to reading efficiency. The studies have also been found that a low rate of implementation of lexical decision tasks is a strong predictor of dyslexia. These studies indicate that the slow decoding rate may damage reading fluency. Additional studies dealt with cognitive resources to achieve reading fluency. These studies provide evidence that there is a general slow pace of processing information among poor readers, which is also apparent in slowness of motor tasks unrelated to written language. Reading, which combines many complex cognitive components, was significantly affected by the slow pace of data processing. From that, developed the theory that dyslexia involves an impairment in the central processing system. Therefore, some researchers argue that the naming and reading pace are not affected by a phonological awareness impairment, but rather by general information processing speed (Hudson et al., 2008).

\section{The second hypothesis}

The second hypothesis that holds that using digital books will improve reading comprehension skills (in all dimensions of understanding) in Arabic among Arab pupils, in seventh grade, at state junior high schools, has been corroborated. The corroboration of the second hypothesis is consistent with the literature that claims that the reading process, and in particular, the reading comprehension process, is affected by the platform on which the material or text is read. There is a significant difference between whether the text is read on a digital platform or on traditional platforms such as a normal printed book. Many researchers emphasize that reading is not only identifying or understanding individual words, but rather, reading means broad understanding. Various reading comprehension models describe show that the reader must build a mental representation of the text to understand it. This process requires the integration of multiple data sources, ranging from lexical characteristics to information related to world events (Sesma et al., 2009).

This finding is very interesting given the refutation of the first hypothesis which engaged in reading fluency. However, we can still explain it by considering that factors that influence the development of reading fluency among students are not the same as those affecting the development of reading comprehension. The development of students' reading comprehension skills depends on a variety of direct and indirect factors that affect the process. The current findings clearly show that the digital book is one of these factors. Moreover, one of the significant factors affecting comprehension is the reading process, which is apparently affected by the digital book. The various studies show that reading comprehension is a complex skill because it requires coordination among many cognitive processes. According to the "simple reading comprehension model" 
(Katzir, Lesaux, \& Kim, 2009), decoding capability and verbal comprehension, which are based on the student's vocabulary, are predictors of reading comprehension. In other words, good understanding of the text requires the ability to read quickly and accurately, in combination with the ability to interpret lexical information. According to this model, the reader must first control eye movements while reading, in order to focus on the written text vision. After a quarter of a second, there is rapid movement of the eyes which focus on the following word and so on. The reader must determine the amount of time sufficient to provide a visual focus as well as determine the next focus point. The next stage is identifying the word. When focusing his vision, the reader translates the complex of letters into a whole object located in the mental lexicon composed of thousands of items. This stage takes a fifth of a second. At the same time, the reader processes information about the next word and the location of the word following that. After identifying the word, the reader decides what the word means, and then connects multiple words together. The reader must dismantle the sentence into its syntactic components, in order to determine the syntactic function of every word and thereby determine the relationship between words. When the sentence is whole, the reader uses his knowledge of the world to determine the general meaning. Ultimately, the reader decides what to do with the new information, and decides whether it is relevant and should be combined with existing data. There is a difference in the predictive ability of the simple model when comparing beginner readers and advanced readers and when comparing readers without reading disability to those with a reading disability (Johnston \& Kirby, 2006; Tiu Jr., Thompson, \& Lewis, 2003).

In addition to everything stated the above, it is possible to interpret the corroboration of the second hypothesis based on the research consensus that the simple model comprehensively explains reading comprehension among struggling junior high school students. However, there is agreement that when the complexity of the text increases, the reader must activate additional skills in order to understand it. The simple model does not include high processes of drawing conclusions, vocabulary, ability to switch between different points of view and so on, which are required when dealing with complex reading comprehension. In addition, there are a number of strategies that proficient readers use for effective comprehension. Beyond identification, there are strategies that the reader deploys proactively, such scanning the text before reading it and setting goals. Also, proficient readers are able to interpret unfamiliar words and perform a comparison between the current information know to them and new information provided in the text. In addition, they exert control processes over their comprehension (Sesma et al., 2009).

The computerized learning platform (in the form of digital books) assists students who find it difficult to concretely and substantively connect between one sentence and the next sentence. In this context, Perfetti and Stafura (2014) consider the process of reading comprehension as building a mental representation 
of the text at the word level, the sentence and whole text. There is a consolidation of the text at the local level by linking a sentence to the next sentence. There is also an integration of events, activities and different ideas that unify the text at the global level. The reader activates deduction processes, integrating knowledge derived from text and general knowledge that the reader already has. In this way, the reader constructs a representation of the world described in the text. This process requires different types of skills such as word deciphering and identification skills, language skills allowing literal comprehension of the text, and high-level processes of constructing conclusions that support complex comprehension processes. According to the approaches described above, in the comprehension process, the reader relies on prior knowledge, draws conclusions, reveals structural and semantic ambiguity, and performs integration of many cognitive and linguistic skills with past knowledge and cultural knowledge.

It is also possible to explain the corroboration of the hypothesis through the componential approach. This approach offers a broad perspective on the processes of reading comprehension supported by numerous studies showing that additional language and literacy such as naming, reading fluency, various indices of production of spoken language and writing skills, explain the differences observed in reading comprehension among students (Johnston \& Kirby, 2006). One may argue that these elements are affected by the platform from which the struggling student reads. Namely, they are affected positively when reading from a digital book. Cain \& Oakhill (Cain \& Oakhill, 2006), who are advocates of the componential approach, suggest that the comprehension process involves higher cognitive processes that contribute to the formation of a mental model of the text. Scientific evidence suggests that abilities such as memory, IQ and attention (Mayes, Calhoun, \& Crowell, 2000) assist in explaining reading comprehension. These studies testify to the complexity of reading comprehension, because a variety of factors predict reading comprehension and link it to high and complex processes. Most of the models address mainly verbal and lingual knowledge that contributes to comprehension, but there are basic cognitive abilities involve in this process.

It should be made clear that the basis for corroboration of the second hypothesis is the fact that reading comprehension is not only encoding with listening comprehension, but so much more, i.e. the visual dimension that a digital book provides exerts a very positive impact. Reading comprehension is a process dependent on a socio-cultural context in which the reader understands the text from a perspective that is cultural and based on context, knowledge and perceptions of the world. The text is a complete communications unit, consisting of ideas organized in syntactic units, and the way in which they are organized is compatible with the pragmatics of the text. Reading a text is a process involving a complex cognitive system and requires decoding, reading individual words, extensive linguistic knowledge such as keyword detection and understanding their role and logical function in the text. Reading requires the creation of fast and efficient connections between prior knowledge and new knowledge. There- 
fore, knowledge of the world is of great importance in understanding the text, in tandem with awareness of various texts such as the narrative, poetic and scientific (Wahl \& Tov Li, 1994).

Reading comprehension is a dynamic process, in the wakes of which a mental map of ideas in the text and the contexts among them is created. The mental model created is not limited to words. It combines visual representations and feelings. A good mental model is linked by consistent logical relations. During the creation of the model, the reader combines between previous knowledge acquired in the course of his life, and the knowledge in the text before him. Therefore, the mental model that he created undergoes constant updating during reading. Consequently, there is a high probability that the important units in the texts will be integrated into the emerging mental model. The construction of a mental model out of knowledge occurs in two stages. The first stage is the stage of construction, where new knowledge is structured into a mental model, which maps the new information. In the second phase, which is called the integration stage, the model which was built in the first stage and includes new information, fits in with the reader's world knowledge which was retrieved by reading the text. At this point, relevant information is selected and crystallize into a neat and consistent model. The more cohesive the text, i.e. there is a fixed logical connection between the parts and it contains most of the information needed to understand while maintaining the order, the easier is for the reader to create a consistent mental model. There is a hypothesis that the texts, that allow for the construction of a mental map that is more coherent, are easier to read. Cohesion of the mental map is proportional to the coherence of the text, which is evident in both the local level, namely the creation of connections between adjacent text parts in a logical way, and the global level, namely the creation of connections between ideas scattered throughout the text and key ideas that connect the pieces of information scattered throughout the text. It seems that the process of comprehension involves "up-down" and "down-up" processes, through constant integration between reader and writer. The integration is manifest in mental models that connect previous knowledge and existing knowledge that is understood using existing mental models. The mental model created depends on the nature of the text, the reader and the knowledge that the reader possesses (Perfetti \& Stafura, 2014).

The first incarnation of reading comprehension is mastery of decoding skills and knowledge of the spoken language, which leads to reading comprehension. This approach has been called "simple view of reading" (Katzir et al., 2009). As the study (which relied heavily on interviews with expert readers) progressed, the second incarnation of reading comprehension emerged: comprehension levels. Reading comprehension is not an unequivocal process. Over the years, researchers and educators have understood, that reading comprehension is a spectrum that enables understanding the text at different levels of depth (Cutting \& Scarborough, 2006). Researchers have tried to offer different levels of under- 
standing as means for understanding the complex process of comprehension and as a means of creating a common language for diagnosis of students and their advancement. Each level is characterized by the individual student's depth of understanding and level of interaction with the text. Cushenbery (1988) divided reading comprehension into four general levels, which are arranged in a hierarchical manner: 1) the verbal level (Literal Reading): 2) the interpretative level (Interpretive Reading); 3) the critical level (Critical Reading); 4) and the creative level (Creative Reading).

This study's conclusion is that digital books affect reading comprehension among readers struggling with Arabic orthography. In other words, the platform from which struggling readers read is a factor that affects their reading comprehension, because the reading comprehension process involves the visual (and not just the auditory) dimension. Therefore, the process of reading comprehension among struggling Arab middle school students is influenced by a wide-scale spectrum of internal contextual and cognitive factors, one of which is the text platform.

\section{Study Limitations}

The current study had several limitations. The first limitation results from the use of the convenience sampling method. This method is characterized by a high level of participant availability in order to build the study sample. In addition, this method is considered one of the most accessible and inexpensive. Despite these advantages, the convenience sampling method entails a large number of study biases. The principle one of these biases is a lack of representation of the general study population. In other words, this method does not guarantee that the sample represents equally the general population, something which is certainly detrimental to the ability to supply external reaffirmation for the findings.

The second limitation stems from its correlative nature. The current study examined statistical relationships between variables, but it is not enough to infer causality. In other words, it is not possible to indicate the existence of a causal relationship between the variables, which hinders the validation of findings on the internal level, i.e. giving interpretations that fit the actual situation.

The study's third limitation stems from the fact that it does not address a wide spectrum of other variables, including control variables, moderation and mediation, which can affect to the findings to some extent, i.e. can affect the system of statistical relationships that emerged in this study. This limitation means that it is not possible to reach clear conclusions regarding the extent to which it will be possible to argue that the findings are significant, i.e., relevant to the matter in which the present study is engaged.

\section{Recommendations for Further Research}

Given the current study's limitations, as noted above, it would be appropriate to conduct a number of future studies: 
1) Future research should be conducted in which method with which the participants are sampled using the random-probabilistic, in order to ensure the highest possible degree of representativeness for the general sampling framework, namely the study's population. This will provide for added external validity to the findings.

2) More research is needed, using the quantitative-manipulating paradigm, to examine the causality among the variables and not just the statistical relationships, such as in the present study.

3) Further research using hierarchical regression is needed to examine all of the control variables, the recession and mediation that can affect the variety of statistical relationships among the variables in the study. This will allow us to examine more precisely the various explained dimensions of the dependent variable, using additional independent variables that moderate or broker in the relationships among the variables.

4) Qualitative research is needed to test (through interviews) the variety of factors affecting the current study's variables. Semi-structured in-depth interviews can provide us with a very valid and reliable picture of this issue. Through these interviews it will be possible to know first-hand, what are the complex of factors underlying the phenomenon under study.

\section{Implications for Practice}

- The results of the present study indicate that digital books improve reading comprehension of poor Arabic readers.

- Digital books did not improve fluency and accuracy of reading Arabic.

- It seems that the complexity of the Arabic orthography hindered its improvement in accuracy and fluency, this due to the short intervention period. Maybe a longer intervention period with extensive language experiences may help more these poor Arabic readers.

\section{Conflicts of Interest}

The authors declare no conflicts of interest regarding the publication of this paper.

\section{References}

Abu-Rabia, S. (1999). The Effect of Arabic Vowels on the Reading Comprehension of Second- and Sixth-Grade Native Arab Children. Journal of Psycholinguislic Research, 28, 93-101. https://doi.org/10.1023/A:1023291620997

Abu-Rabia, S. (2007). The Role of Morphology and Short Vowelization in Reading Arabic among Normal and Dyslexic Readers in Grades 3, 6, 9, and 12. Journal of Psycholinguistic Research, 36, 89-106. https://doi.org/10.1007/s10936-006-9035-6

Abu-Rabia, S., \& Abu-Rahmoun, N. (2012). The Role of Phonology and Morphology in the Development of Basic Reading Skills of Dyslexic and Normal Native Arabic Readers. Creative Education, 3, 1259-1268. https://doi.org/10.4236/ce.2012.37185

Abu-Rabia, S., \& Siegel, L. S. (2003). Reading Skills in Three Orthographies: The Case of 
Trilingual Arabic-Hebrew-English-Speaking Arab Children. Reading and Writing, 16, 611-634. https://doi.org/10.1023/A:1025838029204

Almosa, N. (2003). Duality of Issues in Arabic from the Enlightenment Period to Globalization. Dar Alsorok. (In Arabic)

Ang, S. S., Orozco, M., Gijbels, D., \& Van den Bossche, P. (2018). Learning in the Context of Work in a Digital Age: The Use of Digital Media in Informal and Formal Learning Contexts. In C. Harteis (Ed.), The Impact of Digitalization in the Workplace (pp. 87-101). Springer. https://doi.org/10.1007/978-3-319-63257-5_7

Asadi, I. A., Khateb, A., \& Shany, M. (2016). How Simple Is Reading in Arabic? A Cross-Sectional Investigation of Reading Comprehension from First to Sixth Grade. Journal of Research in Reading, 40, S1-S22. https://doi.org/10.1111/1467-9817.12093

Bar-On, A. (2005). Developmental Model for Learning to Read in Hebrew. Department of Communication Disorders, Tel Aviv University.

Cain, K., \& Oakhill, J. (2006). Profiles of Children with Specific Reading Comprehension Difficulties. British Journal of Educational Psychology, 76, 683-696.

https://doi.org/10.1348/000709905X67610

Cooke, C., Philpott, C., Evans, K., \& Spruce, G. (2016). Learning to Teach Music in the Secondary School: A Companion to School Experience. Routledge. https://doi.org/10.4324/9781315621203

Courteau, É., Royle, P., Gascon, A., Marquis, A., Drury, J. E., \& Steinhauer, K. (2013). Gender Concord and Semantic Processing in French Children: An Auditory ERP Study. In S. Baiz, N. Goldman, \& R. Hawkes (Eds.), Proceedings of the 37th Annual Boston University Conference on Language Development (Vol. 1, pp. 87-99). Cascadilla.

Cremer, M. (2013). Accessing Word Meaning: Semantic Word Knowledge and Reading Comprehension in Dutch Monolingual and Bilingual Fifth-Graders. LOT Publications.

Cremer, M., \& Schoonen, R. (2012). The Role of Accessibility of Semantic Word Knowledge in Monolingual and Bilingual Fifth-Grade Reading. Applied Psycholinguistics, 34, 1195-1217. https://doi.org/10.1017/S0142716412000203

Curinga, R. (2014a). Direct and Indirect Effects of Morphological A wareness on Reading Comprehension for Adolescent Spanish-English Emergent Bilinguals.

Curinga, R. (2014b). The Effect of Morphological A wareness on Reading Comprehension: A Study with Adolescent Spanish-English Emergent Bilinguals. City University of New York.

http://www.google.co.il/url?sa=t\&rct=j\&q=\&esrc=s\&source=web\&cd=1\&cad=rja\&uact =8\&ved=0ahUKEwj9_fi3pd3SAhUKDMAKHVHcBBUQFggdMAA\&url=http\%3A\%2F \%2Facademicworks.cuny.edu\%2Fcgi\%2Fviewcontent.cgi\%3Farticle\%3D1029\%26conte xt\%3Dgc_etds\&usg=AFQjCNHhnfxQ5MdLM1tDUAtC456jiZSLBg

Cushenbery, D. C. (1988). Comprehensive Reading Strategies for All Secondary Students. Charles C Thomas Pub Limited.

Cutting, L. E., \& Scarborough, H. S. (2006). Prediction of Reading Comprehension: Relative Contributions of Word Recognition, Language Proficiency, and Other Cognitive Skills Can Depend on How Comprehension Is Measured. Scientific Studies of Reading, 10, 277-299. https://doi.org/10.1207/s1532799xssr1003_5

Deacon, H. S., Kieffer, M. J., \& Laroche, A. (2014). The Relation between Morphological Awareness and Reading Comprehension: Evidence from Mediation and Longitudinal Models. Scientific Studies of Reading, 18, 432-451. https://doi.org/10.1080/10888438.2014.926907

Duff, D. M. (2015). Lexical Semantic Richness: Effect on Reading Comprehension and on 
Readers' Hypotheses about the Meanings of Novel Words. The University of Iowa.

Eshet, Y. (2012). Thinking in the Digital Era: A Revised Model for Digital Literacy. Issues in Forming Science and Information Technology, 9, 267-276. https://doi.org/10.28945/1621

Ferguson, C. A. (1959). Diglossia. Word, 15, 325-340. https://doi.org/10.1080/00437956.1959.11659702

Hanafi, H. F., Said, C. S., Wahab, M. H., \& Samsuddin, K. (2017). Improving Students' Motivation in Learning ICT Course with the Use of a Mobile Augmented Reality Learning Environment. IOP Conference Series: Materials Science and Engineering, 226, Article ID: 012114. https://doi.org/10.1088/1757-899X/226/1/012114

Harris, T. L., \& Hodges, R. E. (1981). A Dictionary of Reading and Related Terms. International Journal of Rehabilitation Research, 4, 602. https://doi.org/10.1097/00004356-198112000-00035

Hohenstein, S. (2013). Eye Movements and Processing of Semantic Information in the Parafovea during Reading. Doctoral dissertation, University of Potsdam.

Huang, Y. M., \& Liang, T. H. (2015). A Technique for Tracking the Reading Rate to Identify the E-Book Reading Behaviors and Comprehension Outcomes of Elementary School Students. British Journal of Educational Technology, 46, 864-876. https://doi.org/10.1111/bjet.12182

Huda, M., Haron, Z., Ripin, M. N., Hehsan, A., \& Yaacob, A. B. C. (2017). Exploring Innovative Learning Environment (ILE): Big Data Era. International Journal of Applied Engineering Research, 12, 6678-6685.

Hudson, R. F., Pullen, P. C., Lane, H. B., \& Torgesen, J. K. (2008). The Complex Nature of reading Fluency: A Multidimensional View. Reading and Writing Quarterly, 25, 4-32. https://doi.org/10.1080/10573560802491208

Ibrahim, R. (2010). Diglossia and Bilingualism in the Context of the Arabic Language: Evidence from Cognitive Research. Megamot, 46, 598-625.

Isakson, C. S., \& Spyridakis, J. H. (2003). The Influence of Semantics and Syntax on What Readers Remember. Technical communication, 50, 538-553.

Johnston, T. C., \& Kirby, J. R. (2006). The Contribution of Naming Speed to the Simple View of Reading. Reading and Writing, 19, 339-361. https://doi.org/10.1007/s11145-005-4644-2

Jones, R. H., Chik, A., \& Hafner, C. A. (Eds.) (2015). Discourse and Digital Practices: Doing Discourse Analysis in the Digital Age. Routledge.

https://doi.org/10.4324/9781315726465

Katzir, T., Lesaux, N. K., \& Kim, Y. S. (2009). The Role of Reading Self-Concept and Home Literacy Practices in Fourth Grade Reading Comprehension. Reading and Writing, 22, 261-276. https://doi.org/10.1007/s11145-007-9112-8

Kieffer, M. J., \& Lesaux, N. K. (2008). The Role of Derivational Morphology in the Reading Comprehension of Spanish-Speaking English Language Learners. Reading and Writing, 21, 783-804. https://doi.org/10.1007/s11145-007-9092-8

Kirby, J. R., Deacon, S. H., Bowers, P. N., Izenberg, L., Wade-Woolley, L., \& Parrila, R. (2012). Children's Morphological Awareness and Reading Ability. Reading and Writing, 25, 389-410. https://doi.org/10.1007/s11145-010-9276-5

Kucirkova, N., Littleton, K., \& Cremin, T. (2017). Young Children's Reading for Pleasure with Digital Books: Six Key Facets of Engagement. Cambridge Journal of Education, 47, 67-84. https://doi.org/10.1080/0305764X.2015.1118441

Lam, K. Y. Y. (2009). The Effects of Morphological A wareness on Reading in Chinese and 
English among Young Chinese Children: A Longitudinal Study. Doctoral Dissertation, University of Toronto.

Maamouri, M. (1998). Language Education and Human Development: Arabic Diglossia and Its Impact on the Quality of Education in the Arab Region. Kwatie International Publisher.

Mayes, S. D., Calhoun, S. L., \& Crowell, E. W. (2000). Learning Disabilities and ADHD: Overlapping Spectrum Disorders. Journal of Learning Disabilities, 33, 417-424. https://doi.org/10.1177/002221940003300502

Milin, P., Divjak, D., \& Baayen, R. H. (2017). A Learning Perspective on Individual Differences in Skilled Reading: Exploring and Exploiting Orthographic and Semantic Discrimination Cues. Journal of Experimental Psychology: Learning, Memory, and Cognition, 43, 1730-1751. https://doi.org/10.1037/xlm0000410

Mohamed, W., Elbert, T., \& Landerl, K. (2011). The Development of Reading and Spelling Abilities in the First 3 Years of Learning Arabic. Reading and Writing, 24, 1043-1060. https://doi.org/10.1007/s11145-010-9249-8

Perfetti, C., \& Stafura, J. (2014). Word Knowledge in a Theory of Reading Comprehension. Scientific Studies of Reading, 18, 22-37. https://doi.org/10.1080/10888438.2013.827687

Pisa (2018). Literacy among 15 Year Old Students in Science, Reading and Mathematics. Israeli Ministry of Education.

RAMA (2017). The Main Findings from the ePirl International Study. Israeli Ministry of Education.

Saiegh-Haddad, E. (2003). Linguistic Distance and Initial Reading Acquisition: The Case of Arabic Diglossia. Applied Psycholinguistics, 24, 431-451. https://doi.org/10.1017/S0142716403000225

Saiegh-Haddad, E. (2004). The Impact of Phonemic and Lexical Distance on the Phonological Analysis of Words and Pseudowords in a Diglossic Context. Applied Psycholinguistics, 25, 495-512. https://doi.org/10.1017/S0142716404001249

Sesma, H. W., Mahone, E. M., Levine, T., Eason, S. H., \& Cutting, L. E. (2009). The Contribution of Executive Skills to Reading Comprehension. Child Neuropsychology, 15, 232-246. https://doi.org/10.1080/09297040802220029

Share, D. L. (2008). On the Anglocentricities of Current Reading Research and Practice: The Perils of Overreliance on an "Outlier" Orthography? Psychological Bulletin, 5, 584-615. https://doi.org/10.1037/0033-2909.134.4.584

Stein, R. E. (2010). Sensitivity to Consonantal Context in Reading English Vowels: The Case of Arabic Learners. The University of Memphis.

Taha, H.Y. (2013). Reading and Spelling in Arabic: Linguistic and Orthographic Complexity. Theory and Practice in Language Studies, 3, 721-727.

https://doi.org/10.4304/tpls.3.5.721-727

Tiu Jr., R. D., Thompson, L. A., \& Lewis, B. A. (2003). The role of IQ in a Component Model of Reading. Journal of Learning Disabilities, 36, 424-436. https://doi.org/10.1177/00222194030360050401

Tondeur, J., Aesaert, K., Pynoo, B., van Braak, J., Fraeyman, N., \& Erstad, O. (2017). Developing a Validated Instrument to Measure Preservice Teachers' ICT Competencies: Meeting the Demands of the 21st Century. British Journal of Educational Technology, 48, 462-472. https://doi.org/10.1111/bjet.12380

Wahl, A., \& Tov Li, A. (1994). The Teacher in the Diagnostic Instruction Process. In A. Wohl, A. Guterman, \& A. Tov Li (Eds.), Principles and Actions in Teaching Reading: Read Units 1-10 (pp. 512-499). Open University. 